\section{Imagens da cidade: o cinema, o espaço público e as transformações da vida urbana no Brasil}

Images of the city: cinema, public space and the transformations of urban life in Brazil

\section{Nicoly Vitorino}

Universidade Federal de Santa Catarina. Instituto de História.

\section{Julia Fernandes}

Universidade Federal de Santa Catarina. Instituto de Artes.

\section{RESUMO}

O estudo apresenta um paralelo entre representações cinematográficas do espaço urbano e as relações sociais entre os sujeitos e o espaço no contexto das fronteiras simbólicas do Brasil contemporâneo. As análises partem da abordagem do cinema enquanto fonte histórica e das teorias de Milton Santos sobre globalização e subdesenvolvimento.

PALAVRAS CHAVE: cinema brasileiro, urbanização, espaço público, subdesenvolvimento, globalização.

\section{ABSTRACT}

This study introduces a parallel between cinematographic representations of the urban areas and the social relations that between people and space; within the context of the symbolical borders of contemporary Brazil. The analysis set from the approach of Cinema as an historical source and from the theories of Milton Santos regarding globalization and underdevelopment.

\section{KEYWORDS:}

Brazilian

cinema, urbanization, public

\section{INTRODUÇÃO}

O cinema brasileiro é marcado pelos traços das condições de produção da cultura no chamado Terceiro Mundo. Suas imagens são impressões do tempo, do espaço e do subdesenvolvimento. A trajetória do cinema no Brasil se dá em grande parte com as produções de baixo orçamento, nas quais muitas vezes o cenário é a cidade, nem todos os sujeitos são atores, e a linha que separa ficção e documentário é tênue; ou não separa; cinema de testemunho. O cinema brasileiro contemporâneo tem sido manifesto e dispositivo, sobretudo com a massificação da tecnologia e a criação de políticas públicas voltadas à cultura, que permitiram que obras audiovisuais fossem produzidas por sujeitos historicamente marginalizados pela cena do cinema; tem se expandido enquanto espaço democrático e é fonte histórica sobre o tempo presente - é mecanismo de concepção da História para além dos meios tradicionais e oficiais.

Para orientar a análise selecionamos um conjunto de filmes e de bibliografias que tem em comum o elemento da vida urbana no Brasil, suas contradições e agentes, e os processos históricos que permearam as mudanças na relação das pessoas com a cidade a partir da virada do século; com a expansão do neoliberalismo pelo Terceiro Mundo e suas consequências na materialidade do dia-a-dia, objeto central das obras fílmicas. Partindo dos textos do historiador Marc Ferro "O Filme, uma contraanálise da sociedade?" (1992) e "A quem pertence as imagens?" (2009) provocase a compreensão do filme enquanto objeto de análise a partir de sua dimensão de discurso, de ideologia e de fonte histórica. Tudo o que compõe o processo de produção, os que o fazem, os que o vêem, o contexto em que é produzido, como escreve o autor: "as relações do filme com o que não é filme". São estes os filmes selecionados: 


\section{- “O Som ao Redor" (2012), de Kleber Mendonça Filho.}

Em um bairro de classe média da capital pernambucana o espaço de uma rua se faz o elemento comum do cotidiano de distintos personagens. O espaço é marcado pelo processo de verticalização da cidade do Recife e pela ascensão de uma nova classe média, que carrega a herança material e as dinâmicas de poder de seu passado colonial. Os encontros e interações entre os personagens são marcados por tensões de classe e pelo medo profundo de uma possível violação de sua vida privada, ou de sua propriedade privada. Entre os sujeitos que ocupam este espaço de trabalho, e outros de residência, se dão conflitos latentes e passivo-agressivos até o momento em que a chegada de dois forasteiros acarreta um acerto de contas de um passado nem tão recente e nem tão longínquo.

\section{- “O Homem das Multidões" (2014) de Marcelo Gomes e Cao Guimarães}

A cidade é protagonista deste enredo sobre as contradições da modernidade e da cidade grande do século XXI. Marcada pela repetição e pelo ritmo das aglomerações urbanas e da movimentação dos fluxos de pessoas, a narrativa está sempre permeada pelo não-diálogo, o não-olhar e o não-lugar. Os personagens principais, colegas de trabalho que têm em comum o gosto pela isolação e a solidão entre o fluxo do metrô de Belo Horizonte, são sujeitos das dicotomias entre o público e o privado, espaços cheios e vazios, indivíduo e multidão. São significativos os elementos da rotina, da automatização do trabalho e do circular pelo espaço, do não-pertencer, de estar e não-estar no espaço; o silêncio que opera como forma de dizer, e também de calarse, como uma não-ação.

\section{- “Temporada” (2018) de André Novais Oliveira.}

Em frente a uma oportunidade de trabalho, Juliana se muda para a periferia de 120
Contagem, cidade na região metropolitana de Belo Horizonte. No novo lugar, precisa se adaptar a uma nova rotina, um novo emprego, relações com as pessoas que conhece. Através do trabalho de agente de combate a endemias na região, ela passa a circular pelas ruas, frequentar as casas, ter contato com os moradores, e desta forma conhece a cidade e uma rede de relações e de afetos que permeiam o espaço. $\mathrm{Na}$ narrativa, a cidade é personagem e os moradores a reconhecem como tal, percebem nela as ações do tempo e do "progresso", entendem sua marginalização e as marcas destes processos no espaço; que é lugar de comunicação, relações espontâneas e interdependentes, que se distanciam das dinâmicas do neoliberalismo e da moral burguesa, apesar de serem bem marcadas pela urgência do trabalho e pelas adversidades da vida nas periferias dos grandes centros urbanos.

\section{- “Café com Canela “(2018) de Ary Rosa e Glenda Nicácio}

Entre duas cidades do Recôncavo Baiano, se constrói o enredo do filme a partir de um conjunto de crônicas que transpassam no decorrer da narrativa, de início de forma não tão clara. As protagonistas são mulheres que desenvolvem relações de afeto entre si e com o lugar que habitam. O eixo da narrativa é Margarida, uma mulher tomada pelo luto decorrente da perda do filho pequeno, que a mantém em um estado de apatia e isolação paralisante, do qual só consegue se desvencilhar com a ajuda de Violeta, que a reencontra após muitos anos e a convence a sair de casa e tentar retomar a vida. O ambiente da cidade é marcado pelos afetos e pela familiaridade dos sujeitos entre si e com o espaço. Ali se dão relações de trabalho, de lazer, de ócio, e o espaço é além de um lugar de passagem, um espaço de permanência; onde a vida em sociedade dá sentido à vida dos sujeitos.

As obras delimitadas trazem o elemento em comum da cidade, porém apresentam 
diferentes tipos de aglomerações urbanas, as quais apresentam particularidades que são fundamentais para o desenvolvimento da discussão. É elementar a afirmação de Milton Santos: "Cada lugar é, à sua maneira, o mundo." (SANTOS, 2006, p.213). Buscamos identificar os espaços de comunicação e de emoção, que são forças motrizes e lugares de resistência dentro da ambientação da globalização e da tendência à homogeneização da cidade. A partir daí verifica-se um dos eixos norteadores do debate, que é a questão do espaço público como lugar de efervescência luminosa (amparando-nos nas palavras de Milton Santos); e sua tendência à dissolução pelo neoliberalismo e muitas vezes pelo Estado, e ao esvaziamento quando no contexto das classes médias. Consideramos o espaço público palco de grandes ações transformadoras no contexto das cidades no subdesenvolvimento, e por sua importância é talvez esperado que sofra tentativas de desagregação por parte das instituições reguladoras do poder.

Para além desses aspectos, é importante também pensar no filme como um território de movimento, como exprime a noção de "cinema do corpo" de Rogério Sganzerla: "O corpo é um elemento do conflito: há a captação e não sua 'expressão' como tradicionalmente acontece. Estamos diante de um cinema sensorial, de um cinema físico." (SGANZERLA, 1965, p.05). Aí está também a importância da materialidade do espaço no cinema, espaço como personagem, e não como cenário; a câmera que se afasta do drama psicológico do personagem e assim prioriza a dimensão do "acontecimento" e capta impressões da realidade.

Ademais, o que é um filme senão um acontecimento, uma anedota, uma ficção, informações censuradas, um filme de atualidade que coloca no mesmo nível a moda deste inverno e os mortos deste verão; e que poderia fazer disso a nova história (FERRO, 2009, p. 17).

As representações do espaço das cidades nas obras fílmicas selecionadas têm por 122 elemento comum o aspecto de impressões da realidade, tendo em vista que as locações são espaços urbanos de práticas sociais vivas, que podem ou não ter sido isoladas para o contexto da captação das imagens para os filmes. Em "Temporada" podemos perceber com mais clareza a dinâmica da cidade que não pára ou se altera para o contexto do filme: os sujeitos pertencem àquele espaço, circulam por ele e a vida "real" segue seu ritmo, e o filme se desenrola em paralelo. É também no cenário de Contagem que podemos perceber como se desenvolvem as redes de relações e comunicações interdependentes do Estado, do Capital, ou de qualquer instituição que não seja originária deste próprio espaço; fundamentadas nas experiências da emoção, e da escassez.

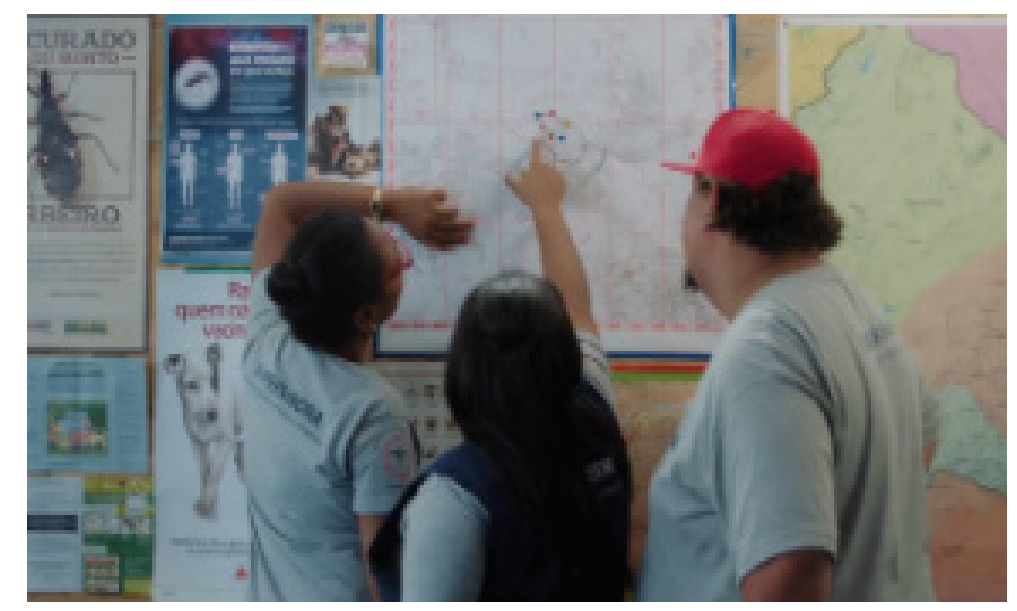

Figura 1: os personagens, agentes de saúde no controle de doenças endêmicas, observam o mapa da cidade. Frame do filme "Temporada", 2018.

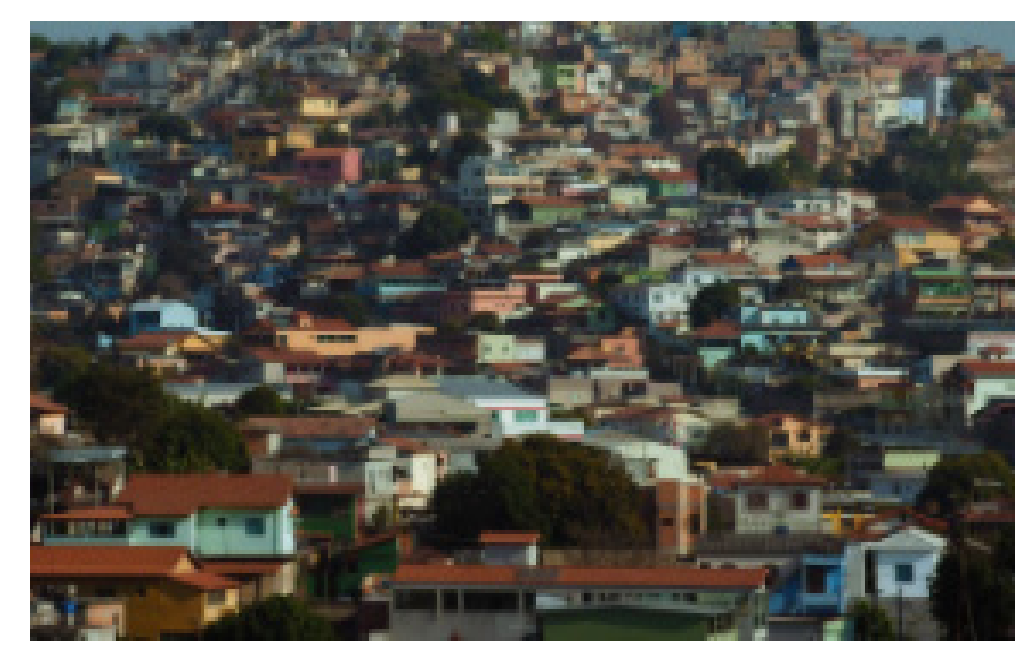

Figura 2: plano aberto da periferia da cidade de Contagem/MG. Frame do filme "Temporada", 2018. 
"OSomao Redor"apresentaasimagens das relações declasseno Brasilcontemporâneo. Verifica-se a particularidade do espaço urbano enquanto lugar de deslocamentos, encontros, e de mobilidade entre diferentes grupos sociais como descreve Milton Santos: "O movimento é potencializado nos países subdesenvolvidos, graças à enorme gama de situações pessoais de renda, ao tamanho desmesurado das metrópoles e ao menor coeficiente de "racionalidade" na operação da máquina urbana." (SANTOS, 2006, p.216). Isso remete ao que o autor conceitua como "flexibilidade tropical", que corresponde às metamorfoses em relação ao trabalho dos pobres nos grandes centros urbanos.

Nas grandes cidades, sobretudo no Terceiro Mundo, a precariedade da existência de uma parcela importante (às vezes a maioria) da população não exclui a produção de necessidades, calcadas no consumo das classes mais abastadas. Como resposta, uma divisão do trabalho imitativa, talvez caricatural, encontra as razões para se instalar e se reproduzir. Mas aqui o quadro ocupacional não é fixo: cada ator é muito móvel, podendo sem trauma exercer atividades diversas ao sabor da conjuntura. (SANTOS, 2006, p.219)

Uma permanente atmosfera de tensão entre os sujeitos marca as interações e até mesmo as cenas estáticas ou em silêncio; aí se vê o medo constante da presença do pobre no espaço da classe média, espaço tomado quase que como sagrado, e a ameaça fantasma e onipresente da violência urbana. O som, e principalmente o som "ao redor", constrói em grande parte esta atmosfera de paranoia e aflição. "O Som ao Redor" retrata as neuroses da classe média, confinada atrás de suas grades, cercas e janelas, em um isolamento paranoico, muitas vezes nas alturas. Uma segregação urbana tão estrutural quanto simbólica, pelo conforto da distância e pelo medo da contradição; que emerge em todos os encontros inevitáveis entre os filhos da casa grande e os que nela (e para ela) trabalham. É uma imagem que expõe a hipocrisia 124 e os vícios da burguesia, que perpetua a desigualdade e a exploração, ao passo que simultaneamente gozam de seu lugar de privilégio e marginalizam as populações periféricas, mantendo o status quo como uma instituição sagrada e impassível.

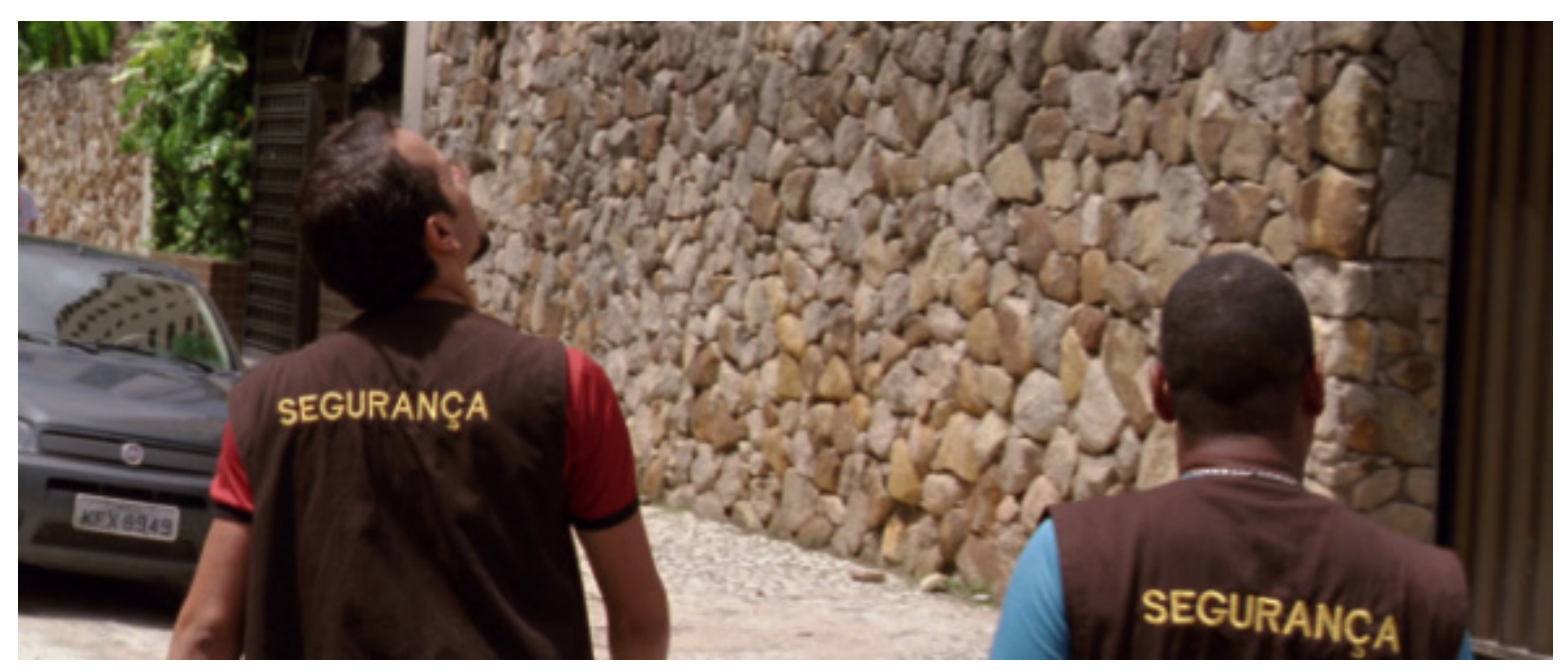

Figura 3: frame do filme "O Som ao Redor", 2013

Um paralelo com o autor Antonio Arantes pode ser feito quando este fala sobre o conceito de "guerra dos lugares". Arantes descreve a existência de um espaço social onde ocorre o embate entre 'dois mundos' que estão em contradição em uma mesma realidade, divididas por fronteiras que ao mesmo tempo "separam práticas sociais e visões de mundo antagônicas e as põe em contato[...]"(ARANTES, 1994, p.194) . A narrativa do filme traz justamente o retrato das fronteiras simbólicas (e não-simbólicas) no espaço urbano, que são espaços de transição, e podem ocorrer no âmbito público ou privado; como as ruas, por exemplo, que correspondem para o autor a lugares de "suportes físicos de significações compartilhadas". (ARANTES, 1994, p.194).

"O Homem das Multidões" marca as relações de trabalho no capitalismo neoliberal da cidade grande: o emprego de Juvenal é garantir que todos os trabalhadores cheguem aos seus empregos. O trabalho estabelece o tempo do capital e do mundo globalizado, a partir de forças verticais as quais são "[...] forças manejadas pelas corporações transnacionais que controlam o sistema mundializado, impondo normas e padrões 
estranhos ao lugar, fragmentando e desfigurando o território."(SEVALHO, 2008, p.10). Na narrativa fica evidente a experiência do tempo lento dos (e pelos) personagens quando estão em seus ambientes privados, ou até mesmo em público; onde se vê a rapidez do fluxo contínuo em si, mas a lentidão nos sujeitos individualmente.

No ambiente do trabalho, justamente, os personagens se relacionam diretamente com máquinas e não com pessoas; e as pessoas que vêem diariamente e com as quais não têm contato direto, são anônimas. Margô, por trás das câmeras, vigia; e Juvenal, a frente dos trens, é também vigiado e está em movimento. A força motriz desse movimento coletivo é marcada pela velocidade como uma característica intrínseca, e, além disso, desejável da modernidade e do sistema técnico hegemônico, que "aparece como algo absolutamente indispensável" (SANTOS, 2008, p. 78)

Das possibilidades de formulação das imagens para pensar a narrativa também em presença material, Marcelo Gomes e Cao Guimarães optaram por construir o filme dentre dicotomias; as espaciais: o metrô cheio, a cidade vazia. As temporais: a noite e o dia. O interior e o exterior, o público e o privado. O corpo-indivíduo e o corpomultidão. A cidade, aqui, é mais entidade operante que apenas plano de fundo, é ela que rege o formato das relações; é um organismo vivo, se espalha incisivamente pelo constante ruído ambiente que dura todo filme, atordoa, mas conforta. Quando o ruído diminui, para evidenciar detalhes sonoros, é que ele mostra sua potência: o intenso som da cidade permite o isolamento no segredo do silêncio.

Figura 4: Juvenal e Margô no silêncio

do espaço privado. Frame do

filme "O homem das multidões", 2014.

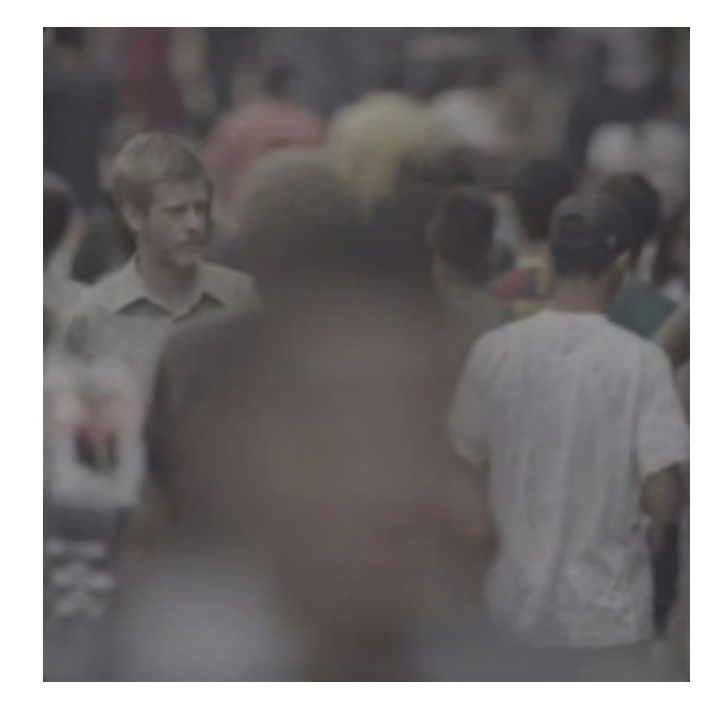

Figura 5: Juvenal caminha entre a multidão. Frame do filme "O homem das multidões", 2014.

Já em "Café com Canela", e também em "Temporada", mas no primeiro de forma mais explícita, reina o tempo lento. Os personagens se deslocam de acordo com a natureza dos acontecimentos e das demandas da vida, que variam; o relógio não dita o ritmo do circular no espaço, que é também lugar de prazer. “Estes são os espaços do aproximativo e da criatividade, opostos às zonas luminosas, espaços da exatidão" (SANTOS, 2006, p221). Se está também em um lugar com o objetivo do desfrute, da interação, da apreciação e contemplação de algo que une os sujeitos, que é a cultura popular. Milton Santos a explana:

A cultura popular tem raízes na terra em que se vive, simboliza o homem e seu entorno, encarna a vontade de enfrentar o futuro sem romper com o lugar, e de ali obter a continuidade, através da mudança. Seu quadro e seu limite são as relações profundas que se estabelecem entre o homem e o seu meio, mas seu alcance é o mundo.(SANTOS, 2006, p.222).

Nas ambientações destes dois filmes podemos ver espaços de comunicação e redes de relações sensíveis entre os sujeitos e dos sujeitos com o espaço. São os espaços 
de efervescência das produções (de todos os tipos) as quais Milton Santos chama de revolucionárias, pois se opõem à violência da informação e à violência do dinheiro. Estas destoam do que se experiência em relação aos espaços da classe média e das partes higienizadas das metrópoles, onde nenhum tipo de relação humana se desenvolve na dimensão de indivíduo coletivo, e de espaço de todos. Nestes espaços, nas periferias e zonas às margens do progresso, há lugar para uma espontaneidade e afetividade que dão sentido aos movimentos dos sujeitos pelo espaço, e sentido ao espaço em si; resistem à racionalização e automatização ou à "mecânica rotineira" (SANTOS, 2006, p. 221).

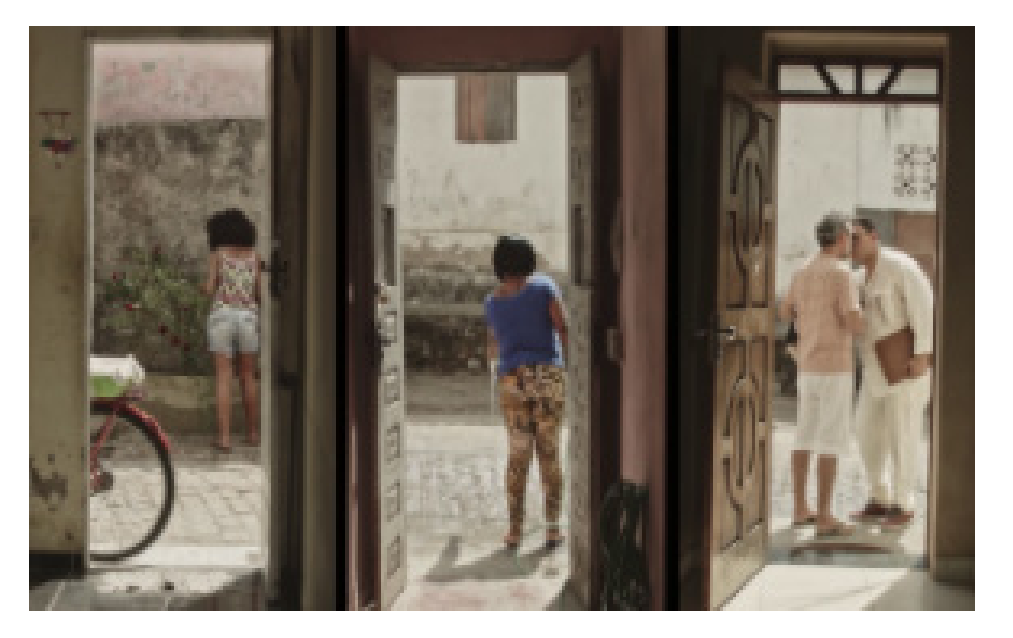

Figura 6: plano aberto dos personagens em frente a suas casas. Frame do filme "Café com canela",

2018.

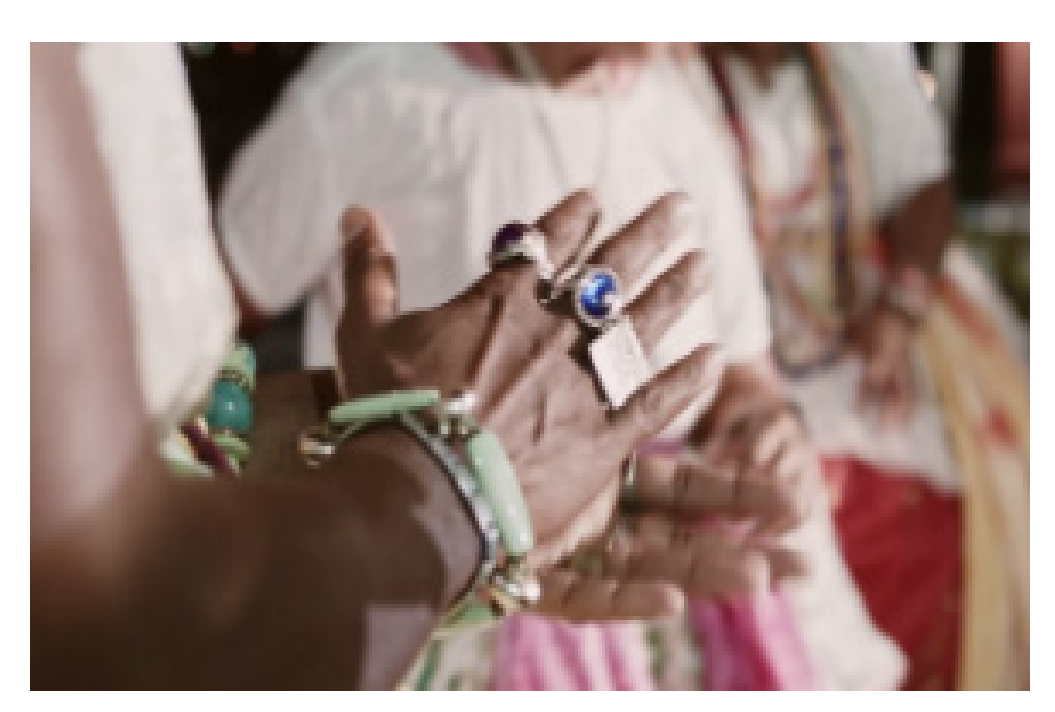

Figura 7: mãos batendo palmas no constexto de uma roda de samba na rua. Frame do filme "Café

\section{CONSIDERAÇÕES FINAIS}

Este ensaio parte da afirmação do Cinema enquanto fonte histórica de observação ativa da contemporaneidade e das urgências que se manifestam no espaço urbano, o qual tomamos como objeto e personagem. Pensar a contemporaneidade é um desafio na medida em que nem sempre se desenrola de forma palpável o historicizar de nosso próprio tempo, justamente pela proximidade inerente ao ato de questionar onde se está, quando e como - com todas as particularidades que o século XXI coloca de forma inédita.

Não é possível distanciar a discussão desse ensaio das questões sobre o capitalismo e o colonialismo, já que estes permeiam toda e qualquer relação dentro do contexto de um país como o Brasil, no qual cada grande cidade reproduz de certa forma o sistema mundo como está dado, com suas zonas luminosas e opacas, e em dimensões variadas. Quando Milton Santos afirma que cada lugar é, à sua maneira, o mundo, não o diz de forma metafórica ou intentando uma alegoria, mas para lembrar-nos de que é impossível fugirmos da dimensão que nos coloca na periferia da grande cidade que é o mundo do Capital; e que também, e mais importante: que são nestas 'zonas opacas' em que se dão as produções revolucionárias que dão sentido à vida como a conhecemos.

Num país como o Brasil a discussão do espaço público se faz urgente pela necessidade de reconhecermos a importância das ações que se dão nos lugares onde as pessoas podem se encontrar livremente, em um espaço que Ihes é por direito. E reconhecer o direito não apenas de transitar ou estar livremente, mas o direito ao lazer, à dignidade e à soberania; já que as instituições externas não agem em seu favor, que ao menos não operem contra. Percebe-se a intervenção do Estado na cidade não de forma a desenvolver políticas em prol dos sujeitos que a ocupam no âmbito público, mas com o objetivo de fazer com que a cidade seja um espaço de consumo. E isto é em 
si um discurso político, e uma afirmação de poder, que transcende o próprio Estado. O capitalismo opera para que o consumo se torne objeto central do estar na cidade; e aí está a iminência do espaço público, para que os corpos possam circular pela cidade e ocupá-la sem que o dinheiro seja o agente mediador de sua presença.

As obras fílmicas que analisamos colocam em nosso campo de visão os espaços públicos que se tornam caminhos, lugares de passagem automática e não de se estar, ou de reconhecer como seu em direito. E esse movimento se dá historicamente pelas recorrentes tentativas de higienização dos espaços da cidade, onde certos corpos podem estar e outros são impedidos; em demarcações pautadas por raça e classe. É possível pensarmos também no desenvolvimento cada vez mais intenso de espaços de coerção e de controle; a partir dos mecanismos de vigilância em massa assegurados pela tecnologia do Capital e aclamados pelos órgãos de segurança dos governos. Estes processos explicam, em parte, o contexto dos cenários urbanos que vemos retratados nos filmes que analisamos.

Entendemos que ainda nos encontramos nas mesmas circunstâncias do subúrbio da globalização - das quais reitera sempre Milton Santos no fim do século XX e que foram retratadas nas narrativas do Cinema Marginal - apesar da ascensão das novas elites econômicas e das classes médias que tentam atestar o contrário. O Brasil é transpassado pela dimensão do subdesenvolvimento e está longe de superá-la, mas ao mesmo tempo tem se aproximado do movimento urgente de reconhecer-se como tal e tomar para si esta potência de criação; e isto podemos observar nas produções do Cinema Nacional desta década, que se mantém vivo! apesar das dificuldades materiais de produção e dos boicotes dentro do contexto sócio-político.

Reiteramos a importância das políticas públicas, que permeiam todos os âmbitos desse ensaio. Necessitamos de políticas públicas que possibilitem a pesquisa acadêmica na universidade pública, políticas públicas que viabilizem a produção do 130 cinema nacional, políticas públicas que assegurem a existência dos espaços públicos e democráticos, entre outros direitos que se fazem urgentes frente à força do capital mundial e do neocolonialismo.

\section{REFERÊNCIAS}

ARANTES, Antonio. “A guerra dos lugares". in: Revista do Patrimônio Histórico e Artístico. Nacional. IPHAN. n 23. Pps.: 190-203. 1994.

COSTA, Jorge R. Santos de Lima. A paixão de olhar: a cidade no cinema brasileiro. 2008.

FERRO, Marc. "O filme, uma contra-análise da sociedade?" In: FERRO, Marc. Cinema e história. Rio de Janeiro: Paz e Terra, 1992, p. 79-115.

FERRO, Marc. "A quem pertence as imagens?" In: NÓVOA, J.;FRESSATO, S.; FEIGELSON,

K. Cinematógrafo: um olhar sobre a História. Salvador: EDUFBA, São Paulo: Ed. da Unesp, 2009, p. 15- 25.

ROCHA, Glauber. "A eztetyka da fome" (1965). In: ROCHA, G. Revolução do cinema novo. Rio de Janeiro: Alhambra/Embrafilme, 1981.

SALES GOMES. Paulo Emílio. Cinema: trajetória no subdesenvolvimento. São Paulo: Paz e Terra, 1996.

SANTOS, Milton. "Os pobres na cidade". In: SANTOS, Milton. A natureza do espaço: técnica e tempo, razão e emoção. São Paulo: Edusp, 2006.

SANTOS, M. Técnica, espaço e tempo: globalização e meio técnico-científico informacional. 2.ed. São Paulo: Hucitec, 2008.

SANTOS, M. 0 tempo nas cidades. Coleção Documentos: Série Estudos Sobre o Tempo, IEA - USP. São Paulo, n.2, 1991.

SEVALHO, Gil. "O homem dos riscos e o homem lento". Interface - Comunic., Saúde, Educ., v.16, n.40, p.7-19, jan./mar. 2012. 
SGANZERLA, Rogério. “Cineastas do corpo”. Jornal O Estado de S. Paulo. São Paulo:

26 jun. 1965. Suplemento Literário, p. 5. 